Doğan, E. ve Afşar, A. (2021). “Politik ve Jeopolitik Riskler Hisse Senedi Piyasalarını Nasıl Etkiler: Yükselen Piyasa Ekonomilerinden Ampirik Kanıtlar", Eskişehir Osmangazi Üniversitesi iïB Dergisi, 16(3), 688 - 704.

Doi: 10.17153/oguiibf.952112

Başvuru: 14.06.2021 Kabul: 09.08.2021

Araştırma Makalesi/Research Article

\title{
Politik ve Jeopolitik Riskler Hisse Senedi Piyasalarını Nasıl Etkiler: Yükselen Piyasa Ekonomilerinden Ampirik Kanıtlar ${ }^{1}$
}

Emrah Doğan²

Aslı Afşar ${ }^{3}$ (iD

\begin{abstract}
Politik ve Jeopolitik Riskler Hisse Senedi Piyasalarını Nasıl Etkiler: Yükselen Piyasa Ekonomilerinden Ampirik Kanitlar
\end{abstract}

Öz

Bu çalışmada yükselen piyasa ekonomilerinde politik risk ve jeopolitik risklerin hisse senedi piyasaları üzerindeki etkileri araştırılmıştır. Çalışmada 2005-2018 yılları arasındaki verileri içeren panel veri seti kullanılmıştır. Ekonometrik yöntem olarak Temel Bileşenler Analizi (PCA) yöntemi ve Parks-Kmenta Tahmincisi kullanılmıştır. Elde edilen bulgulara göre, politik risk ve jeopolitik risk ile hisse senedi piyasaları arasında negatif ve istatistiki olarak anlamlı bir ilişki olduğu gözlemlenmiştir. Bu bağlamda, bu çalışmanın bulguları, yükselen piyasalar ekonomilerine yönelik yüksek risk algılarının hem yerli hem de yabancı yatırımcıların hisse senedi piyasalarına yapacakları yatırımları sınırlandırdığını ifade etmektedir.

Anahtar Kelimeler: Hisse Senedi Piyasaları, Politik Risk, Jeopolitik Risk, Panel Veri Analizi

JEL Kodları: O15, 016, G20
How Political and Geopolitical Risks Affect Stock Markets: Empirical Evidence from Emerging Market Economies

\section{Abstract}

This study investigates the effects of political and geopolitical risks on stock markets in emerging market economies. A panel data set containing data between the years 2005-2018 was used in the study. Principal Component Analysis (PCA) method, Parks-Kmenta Estimator, and were used as an econometric method. According to the findings, it has been observed that there is a negative and statistically significant relationship between both political risk and geopolitical risk and stock markets. In this context, the findings of this study indicate that high-risk perceptions towards emerging markets economies limit the investments of both domestic and foreign investors in stock markets.

Keywords: Stock Markets, Political Risk, Geopolitical Risk, Panel Data Analysis

JEL Codes: O15, O16, G20

\begin{tabular}{cc}
\hline \hline $\begin{array}{c}\text { Araştırma ve } \\
\text { Yayın Etiği } \\
\text { Beyanı }\end{array}$ & Bu çalışma bilimsel araştırma ve yayın etiği kurallarına uygun olarak hazırlanmıştır. \\
$\begin{array}{c}\text { Yazarların } \\
\text { Makaleye }\end{array}$ & $\begin{array}{c}\text { Çalışmanın tamamı iki yazar ile birlikte/bölümleri yazarlara paylaştırılarak oluşturulmuştur. Bununla birlikte birinci } \\
\text { Olan Katkıları }\end{array}$ \\
ve ikinci bölümleri Aslı Afşar; analiz içeren kısımlar Emrah Doğan tarafından yapılmıştır. \\
Çıkar Beyanı & Yazarlar açısından ya da üçüncü taraflar açısından çalışmadan kaynaklı çıkar çatışması bulunmamaktadır. \\
\hline \hline
\end{tabular}

\footnotetext{
${ }^{1}$ Bu çalışma 22. Finans Sempozyumu’nda sunulan “Politik Risklerin Hisse senedi Piyasaları Üzerine Etkileri: Ampirik Bir Analiz" başlıklı bildirinin gözden geçirilmiş ve genişletilmiş versiyonudur.

${ }^{2}$ Dr. Öğr. Üyesi, İstanbul Gelişim Üniversitesi, İktisadi ve İdari Bil. Fak., Uluslararası Ticaret ve Finansman (İngilizce) Bölümü, emdogan@gelisim.edu.tr

${ }^{3}$ Prof. Dr., Anadolu Üniversitesi, Eskişehir MYO, Dış Ticaret Programı, aafsar@anadolu.edu.tr
} 


\section{Giriş}

Finansal piyasaların serbestleşmesi ve sermaye piyasalarının küreselleşmesi, finansal hizmetleri ve yatırımlarını geliştirmiştir. Aynı zamanda bu durum ulaşılabilir ve karlı yatırımların ülkelere gelmesinde belirgin bir etken olmuştur. Ulaşılabilir ve karlı yatırımların ülkeye gelmesinde birçok faktör bulunmaktadır. Bu faktörler arasında, ülkenin piyasa yapısı, ekonomik ve finansal istikrarı, döviz kuru riskleri gibi makroekonomik göstergeler yer almaktadır. Bunun yanı sıra yatırımcılar için belirsizlik unsurunun artması ulaşılabilir ve karlı yatırımların belirlenmesi aşamasında önemli yer tuttuğundan finansal piyasalar üzerine önemli etkileri olmaktadır. Bu belirsizliklerin tespitinde en temel belirleyicilerden biri ise ülkelerin risk düzeyidir. Bilindiği üzere yabancı yatırımlar için ülkelerin risk düzeyinin yüksek olması bir belirsizlik unsuru yaratmaktadır. Bu durum ise yatırımcıların ya mevcut yatırımlarından vazgeçmesine ya da yatırım planlarının ertelenmesiyle sonuçlanabilmektedir. Bu doğrultuda düşünüldüğünde ülke risklilik düzeyini oluşturan unsurlardan, politik ve jeopolitik risklerin hisse senedi ve dolayısıyla finansal piyasalar üzerindeki etkilerine ilişkin bir yaklaşım geliştirmek önemlidir.

Yatırımları etkileyen faktörlerden risk düzeyinin ana unsurlarından politik riskin kabul edilen tek bir tanımı olmamakla birlikte, alıcı ülkede meydana gelen politik olaylardan dolayı, hükümetin yatırım kararlarında meydana getirebileceği beklenmedik değişimler şeklinde ifade edilmektedir (Butler ve Joaquin, 1998). Diğer bir ifade ile politik risk vergi yasalarında ve hükümet politikalarında ani değişiklikler, yurt içi ve yurt dışı çatışmalar gibi siyasi değişimler nedeniyle ulusal ve uluslararası iş ortamında beklenmedik dönüşümler riski olarak açıklanabilir. Yani politik risk, yatırımcılar açısından gerekli geri dönüşü gerçekleştirmeme veya hatta bazı ülkelerin hükümet politikalarında veya düzenleyici ortamlarında meydana gelen değişikliklerden kaynaklanan kayıplar meydana gelme olasılığı anlamına gelir. Ekonomik ve finansal değişkenlerin aksine, politik risklerin nicel olarak ölçülmesi daha zordur (Minovic ve Eric, 2016: 151). Bu noktada politik riski ölçmek ve ülkelerin politik istikrarını göreceli olarak değerlendirmek için Uluslararası Risk Rehberi'nin (International Country Risk Guide, ICRG) Politik Risk bileşenlerine güvenilir (Lehkonen \& Heimonen, 2015: 84).

Finansal piyasalar politikayla ilgili çeşitli olayları uluslararası sermaye akımları aracılığıyla yansıtmaktadır. Politik olaylardan kaynaklı yayılan sinyaller, küresel ölçekte finansal araçların fiyatlarını ve getirilerini etkiler. Bu sebeple, aşırı dalgalanmaların finansal spekülasyonları teşvik etmesi ve uzun vadeli yatırımları engellemesi nedeniyle finansal piyasadaki istikrar modern dünyanın temel önceliğidir (Afşar ve Doğan, 2018). Bu bağlamda değerlendirildiğinde, politik risk alanındaki değişimler uluslararası sermaye akımlarında ani değişim yaratır. Yükselen piyasa ekonomileri bağlamında değerlendirildiğinde, bilindiği üzere bu ekonomilerin sermaye piyasalarına yatırım yapmakla ilgili birçok risk vardır. Bu risk unsurları da ülkeye gelen uluslararası sermeye akımlarında ani değişimlere yol açmaktadır. En önemli risklerden biri, genellikle yatırımın önündeki en büyük engellerden biri olan politik nedenlerden kaynaklanmaktadır (Bekaert vd. 2014; Estrin ve Uvaliç, 2013). Bu ülkelerin birçoğunun tasarruf sorunu olduğu için, politik risk seviyesinin yabancı yatırımcılar için kontrol altında tutulmalıdır. Çünkü ekonomik ve politik ortamın istikrarsız olduğu yükselen piyasalar, politik risklere olan yüksek duyarlılığı nedeniyle hızla etkilenebilmektedir. Bu ise istikrarsız fiyat dalgalanmalarına neden olmaktadır. 
Yükselen piyasaların genellikle gelişmiş piyasalardan daha az entegre olduğu gözlenmektedir. Bunun ise entegrasyon engellerinden kaynaklandığı söylenebilir. Söz konusu bu engellerin makro ekonomik ya da piyasaya özgü olduğu öne sürülmektedir (Bekaert vd., 2014). Bu engeller aynı zaman politik riske de katkıda bulunur. Makroekonomik engeller, zayıf kredi notları, yüksek ve değişken enflasyon, değişim kontrolleri, ekonomi politikası, likidite riski ve kur riski ile ilgilidir. Piyasaya özel engeller, uluslararası brokerlerin, piyasa büyüklüğünün, düzenleyici ve muhasebe sistemlerinin varlığı açısından piyasanın hangi dereceye kadar geliştirildiğinden etkilenir (Af̧̧ar ve Doğan, 2018). Yükselen piyasa ekonomilerindeki hisse senedi piyasaları gelişmiş ekonomilerdekinden farklıdır. Dolayısıyla yükselen ve gelişmiş piyasalar arasındaki farklılıklar ile ilgili olarak öne sürülen birçok faktör, politik risk unsurlarıyla da ilgilidir. Bu nedenle, yükselen piyasalar, politik riskin hisse senedi piyasaları ve getirileri üzerindeki etkisini incelemek için iyi bir ortam yaratmaktadır (Bilson vd., 2002: 4-5).

Yatırımcıları etkileyen risklerden bir diğeri ise jeopolitik risktir. Jeopolitik risk; ülkelerin veya kurumların bulundukları bölgeyi kontrol ederken veya rakipleriyle rekabet ederken ortaya çıkan sorunların barış̧ıl yollarla çözülemediği durumlarda meydana gelen ve ülkenin refahını etkileyen her türlü gerilim, savaş ve terörist faaliyetler ile ilişkilidir. Bu çerçevede jeopolitik risk kavramı; ülkede yaşanan siyasi faaliyetler neticesinde ortaya çıkan siyasi kargaşanın, kurumsal mücadele ve davranışların, demokratik olmayan süreçlerle çözüldüğü durumda ortaya çıkan riski ifade etmektedir (Caldara ve Lacoviello, 2018: 8). Dolayısıyla jeopolitik risk, uluslararası ilişkileri etkileyen ulusal veya devletler arası her türlü gerilimli eylemleri içeren bir kavram olmakla beraber, ülkenin dış faktörler nedeniyle yükselen riskini ölçmektedir. Bu çerçevede değerlendirildiğinde yatırımcılar, şirket yöneticileri, analistler, ülkedeki ekonomi ve maliye politikasına yön verenler, jeopolitik risk düzeyini yatırım kararlarının önemli bir belirleyicisi olarak görmektedirler (Çetin, 2019: 109). Çünkü ülkelerin sahip olduğu yüksek jeopolitik risk, reel ekonomik faaliyetlerin gerilemesine neden olmaktadır. Bu ise yatırımcılar için daha düşük getiri anlamına geldiğinden yüksek jeopolitik risk, yatırımları dolayısıyla finansal piyasaları doğrudan etkilemektedir.

Bu çalışmanın amacı, politik ve jeopolitik risklerin hisse senedi piyasası üzerinde etkisi olup olmadığını tespit etmektir. Bu amaçla çalışmada, 11 yükselen piyasa ekonomisinde politik risk ve jeopolitik risk ile hisse senedi piyasaları arasındaki ilişkinin araştırılması hedeflenmiştir. Bu ise 2005-2018 yılları arasındaki verileri içeren panel veri seti ve Temel Bileşenler Analizi (PCA) yöntemi, Parks-Kmenta Tahmincisi yardımıyla gerçekleştirilmiştir. Çalışmayı diğer çalışmalardan ayıran özelliklerden biri, ülkelerin risk düzeylerinin finansal piyasalara etkileri üzerine yapılan yoğun tartışmalar göz önüne alındığında çalışmanın bu tartışmalara ampirik bir katkı sağlayacak olmasıdır. Çalışmayı diğer çalışmalardan ayıran diğer bir özellik ise, yükselen piyasalar ekonomileri için ICRG'nin Politik Risk bileşenlerinden hareketle yeni bir politik risk endeksinin oluşturulmasıdır. Bu çerçevede değerlendirildiğinde, çalışmanın literatüre önemli katkı sağlayacağı düşünülmektedir.

Çalışmada öncelikle çalışmanın konusu ile ilgili yapılmış geçmiş çalışmaların bulgularının ortaya konduğu literatüre yer verilmiştir. Daha sonra ise çalışmada kullanılan veri seti ve yöntemi tanıtıldıktan sonra çalışma da elde edilen ampirik bulgular ortaya konmaktadır. Nihai olarak ise, çalışmada elde edilen bulguların değerlendirilmesine ve önerilere yer verilmiştir. 


\section{Literatür}

Hisse senedi piyasaları bağlamında risk ile ilgili çalışmalar 1990'ların ortalarına kadar uzanmaktadır. Ancak çalışmanın bu risk unsurlarının en önemli iki bileşeni olarak incelenen politik ve jeopolitik risk unsurlarının hisse senedi piyasaları üzerine etkilerine yanıt aradığından bu iki bileşene yönelik çalışmalara odaklanmaktadır. Dolayısıyla bu sayede politik ve jeopolitik risklerin hisse senedi piyasalarını nasıl etkilediğine yönelik daha güvenilir çıkarımlar yapmak mümkündür.

Literatürdeki çalışmalardan bazıları riskleri politik boyutta ele alarak, politik risklerin hisse senedi piyasalarını nasıl etkilediği sorusuna yanıt aramıştır. Bu çalışmalardan Diamonte vd. (1996), politik riskin gelişmekte olan ve gelişmiş ülkelerdeki hisse senetlerinin istikrarsızlıklarından sorumlu en önemli itici güçlerden biri olduğunu, ancak gelişmekte olan ekonomilerde politik belirsizliğin daha büyük bir rol oynadığını kanıtlamışlardır. Bu sonuçlar De Santis ve İmrohoroğlu (1997) tarafından da doğrulanmıştır. Mei ve Guo (2004) ise politik risklerin finansal piyasaların istikrarı üzerinde ne yönde etkilediği sorusuna yanıt aramış ve politik risklerden kaynaklı istikrarsızlıkların finansal krizleri tetikleyecek derecede önemli bir faktör olduğunu sonucuna ulaşmışlardır. Politik iş döngüsünün borsalardaki volatilite üzerinde hayati etkisi ABD ekonomisinde de doğrulanmıştır (Gärtner \& Wellershoff, 1999).

Perotti ve Oijen (2001), politik risklerdeki değişikliklerin, gelişmekte olan ekonomilerde yerel borsa gelişimi ve aşırı getiriler üzerinde güçlü bir etkiye sahip olduğunu yaptıkları analizle doğrulamıştır. Ayrıca yazarlar başarılı özelleştirmeden kaynaklanan politik risk çözümünün gelişmekte olan ülkelerdeki hisse senedi piyasalarının hızlı büyümesi için önemli bir kaynak olduğu sonucuna varmışlardır. Perotti ve Oijen (2001) ile benzer şekilde Bilson vd. (2002), birçok gelişmekte olan piyasanın, özellikle Pasifik Havzası'ndaki politik risk ve hisse senedi getirileri arasında önemli bir ilişki sergilediği sonucuna ulaşmıştır. Ayrıca Kaya vd. (2014) ve Çam (2014), Tükenmez ve Kutay (2016), Tuncay (2018) de politik risklerin hisse senedi fiyatlarını ve dolayısıyla hisse senedi piyasasını etkileyen önemli faktörlerden biri olduğunu yaptıkları çalışmalarla doğrulamıştır.

Lehkonen ve Heimonen (2015), politik risklerin hisse senedi piyasalarında elde edilen getirileri etkileme derecesini incelemiştir. Buna göre yazarlar politik risklerin daha düşük seviyede olmasının, hisse senedi piyasalarında sağlanacak getirilerin daha yüksek olmasında önemli oranda etkili olduğunu kanıtlamışlardır. Bu çalışmada ulaşılan sonuçlar Tolstova ve Kapolková (2015) tarafından da doğrulanmıştır. Tolstova ve Kapolková (2015)’ya göre politik risk, borsa performansında özellikle de fiyat-kazanç oranı ve temettü getirilerini önemli derecede etkileyen bir faktördür.

Dimic vd. (2015), diğer çalışmalardan farklı olarak politik riski oluşturan bileşenlerin hisse piyasaları üzerinde etkisi olup olmadığı araştırma sorusuna yanıt aramışlardır. Yapılan analizler sonucunda hisse senedi piyasalarını etkileyen temel politik risk kaynağının hükümet istikrarı olduğunu doğrulamıştır. Bununla birlikte özellikle gelişmekte olan ülke hisse piyasalarının demokratik hesap verebilirlik, orduya ilişkin riskler, yolsuzluk ve yatırım profili gibi politik risk unsurlarına duyarlı olduğunu vurgulamışlardır. Minovic ve Eric (2016) ise Dimic vd. (2015)'i doğrular şekilde politik hisse senedi piyasalarında etkili olan temel politik risk bileşeninin hükümet istikrarı olduğunu vurgulamıştır. Buna ilaveten politik risk seviyesinin düşürülmesinde daha güçlü kurumlar, mülkiyet koruması ve istikrarlı düzenlemelere ihtiyaç olduğunu belirtmiştir. Kobbi ve Abdelhedi (2018) çalışmalarında, kayıt dışı politik istikrarsızlığın (suikastlar ve devrim), resmi siyasi istikrarsızlığın (büyük hükümet krizleri ve bazı 
anayasal değişiklikler) finans piyasalarında terörün olumsuz etkilerine destek olduğu vurgusu yapmışlardır. Ayrıca, çalışmada Minovic ve Eric (2016) ile Dimic vd. (2015) farklı olarak, kayıt dışı politik istikrarsızlığın (suikastlar ve devrim) hisse senedi piyasalarında daha önemli derecede etkileyen bir politik risk bileşeni olduğunu belirtmiştir.

Vortelinos ve Saha (2016) politik riskin bölgesel bazda hisse senedi piyasalarının etkilerini tespit etmeye çalışmışlardır. Çalışmada ulaşılan sonuçlar Amerika ve Avrupa bölgesinin politik risklere önemli oranda duyarlı olduğunu göstermektedir. Bununla birlikte özellikle Kuzey Amerika bölgesi, finansal piyasaları en çok politik risklerden etkilenen bölge olarak görülmektedir. Dolayısıyla söz konusu bu çalışma ışı̆̆ında gelişmekte olan ülkeler kadar gelişmiş ülke finansal piyasalarının da politik risklerden etkilenerek istikrarını kaybettiği değerlendirmesi yapmak mümkündür. Waszkiewicz'in (2017) de Vortelinos ve Saha (2016)'yı destekleyici şekilde gelişmiş ve gelişmekte olan ekonomilerde ulusal finansal piyasalarının politik riskten önemli oranda etkilendiğini ifade etmiştir. Bunun en önemli nedeni finansal piyasalara yatırım yapan yatırımcıların ulusal hükümetler kadar politik riske maruz kalmasıdır. Ancak burada önemle belirtilmesi gereken bulgu bunlar arasında potansiyel etkinin büyük farklılıklar göstermesidir. Gelişmiş ekonomiler göreceli olarak düşük politik risklere sahiptir, ancak bu tehdit terörizm, silahlı çatışmalara katılım ve siber saldırı nedeniyle finansal piyasalarda değişkenlik yaratabilmektedir. Bunun bir nedeni finansal olarak küreselleşmiş finansal piyasaların, önemli uluslararası sermaye akımlarını ve risk azalmasını desteklemektedir, ancak finans içindeki politik ve istikrarsızlık alanından kaynaklanan tehditlerin bulaşmasından dolayı çoğunlukla finansal akımlardaki dalgalanmalara katkıda bulunmasıdır. Öte yandan, gelişmekte olan ekonomilerin, politikayla ilgili alanların ve küresel finans ile ulusal finansal piyasa entegrasyonunu iyileştirmekle birlikte, politik risk alanından gelen tehditlere karşı daha duyarlı hale geleceğini bildirmiştir. Vargas ve Silva (2019)'un küresel politik riskteki artışın küresel hisse senedi getirileri ile negatif korelasyon ilişkisi gösterdiği yönünde bulguları da bahsi geçen bu tespitleri doğrular niteliktedir.

Litaratürdeki çalışmalardan bazıları ise bu çalışmanının da konusunu oluşturan risk unsurlarından jeopolitik riskin hisse senedi piyasalarına etkileyip etkilemediği sorusuna yanıt aramıştır. Bahsi geçen az sayıdaki jeopolitik riskin hisse senedi piyasaları üzerine etkilerinin araştırıldığı çalışmalardan Das vd. (2019), jeopolitik riski ekonomik belirsizlik, finansal stres gibi unsurlarla karşılaştırmıştır. Buna göre jeopolitik riskin hisse senedi piyasası üzerinde etkisi bulunmakla birlikte ekonomilerin sahip olduğu belirsizliklerin hisse senedi piyasaları üzerinde daha güçlü bir etkisi olduğu tespiti yapılmıştır. Yine jeopolitik riskleri küresel düzeyde ele alan Hoque ve Zaidi (2020), küresel jeopolitik riskin yarattığı belirsizliğinin borsa performansını hem olumlu hem de olumsuz yönde etkileyebileceğini, bunun da eşzamanlı zamana, gecikme süresine, oynaklık rejimlerine ve borsaya bağlı olduğunu belirtmişlerdir. Bezgin (2019) ise, jeopolitik risklerin yarattığı belirsizliklerin hisse senetlerinin istikrarsızlıklarından sorumlu en önemli itici güçlerden biri olduğu tespitinde bulunmuştur. Dolayısıyla hisse senedi piyasalarında jeopolitik risk faktörü ve jeopolitik riske ilişkin gelişmelerin dikkate alınmasının önemi ilgili literatür tarafından da vurgulanmaktadır. 


\section{Model, Veri Seti ve Yöntem}

\subsection{Veri Seti}

Çalışmada, 11 yükselen piyasa ekonomisinde (Arjantin, Çin, Endonezya, Filipinler, Güney Afrika, Hindistan, Kolombiya, Malezya, Meksika, Tayland, Türkiye) politik risk ve jeopolitik riskin ekonomik büyüme üzerindeki etkileri ampirik olarak incelenmektedir. Çalışma kapsamındaki ülkeler, verilerin ulaşılabilirliğine ve Dünya Bankası'nın gelir durumuna göre yükselen piyasalar sınıflandırmasına göre seçilmiştir. Bu bağlamda çalışmada kullanılan veriler 2002-2018 dönemi için Caldara ve lacoviello (2018)'un geliştirdiği jeopolitik risk endeksi veri tabanı ve Dünya Bankası veri tabanından elde edilmiştir. Çalışmada yükselen piyasalar ekonomilerinde ülkelerinde politik riskler ile hisse senedi piyasaları arasındaki ilişkiyi incelerken politik riski temsil etmesi adına politik risk endeksi (pr) kullanılmıştır. Söz konusu endeksle ilgili literatür incelendiğinde farklı çalışmaların, amaçlarına uygun olarak farklı politik risk endeksi ve buna ilişkin farklı risk bileşenlerini kullandıkları görülmektedir. Bu çalışmada, literatürdeki diğer çalışmalardan farklı olarak Uluslararası Risk Rehberi (International Country Risk Guide (ICRG)) PRS Grubu tarafından hazırlanan politik risk bileşenleri verilerini kullanarak yeni bir politik risk endeksi oluşturulmuştur. Yeni bir politik risk endeksi oluşturulmasında temel amaç, politik risk bileşenlerinin göreceli önemini elde ederek daha geniş çapta etkilerin tespit edilmesidir. Çalışmada ele alınan söz konusu politik risk bileşenlerine ise Tablo 1'de yer verilmiştir.

Tablo 1: Politik Risk Endeksi Oluşturmak İçin Kullanılan Göstergeler

\begin{tabular}{cc}
\hline \hline Göstergeler & Kaynak \\
\hline \hline Demokratik Hesap Verebilirlik ve Ifade Özgürlüğü & PRS, Dünya Bankası \\
Politik istikrar ve şiddetin olmaması & PRS, Dünya Bankası \\
Hükümet Etkinliği & PRS, Dünya Bankası \\
Düzenleyici Kalite & PRS, Dünya Bankası \\
Kanun ve Düzen & PRS, Dünya Bankası \\
Yolsuzluğun Kontrolü & PRS, Dünya Bankası \\
\hline \hline
\end{tabular}

Politik risk bileşenlerinin göreceli önemini elde etmek ve yükselen piyasa ekonomileri için politik risk endeksi oluşturmak için çalışmada, politik risk endeksi için seçilen risk bileşenleri çerçevesinde Temel Bileşenler Analizi (PCA) yöntemi uygulanmıştır. Bu yöntem, aralarında ilişki olan $\mathrm{p}$ sayıdaki göstergenin göreceli olarak ağırlığının üretilmesi yardımıyla $\mathrm{k}$ sayıda ilişkisiz değişken geliştirmeyi sağlamaktadır. Bunun için ilk aşamada boyut indirgeyerek yeni bir veri kümesi yaratmaktadır. İkinci aşamada ise ilişkili göstergeleri kullanarak bunlardan ilişkisiz temel bileşenler skorları hesaplamaktadır (Johnson ve Wichern 2002, Tatıdil 2002, Özdamar 2010). Son olarak ise her bir temel bileşeni sıralayarak temel bileşen puanlarının ağılıkları dikkate alınarak politik risk endeksi hesaplanmaktadır.

Çalışmada yükselen piyasalar ekonomisinde jeopolitik risk ile hisse senedi piyasaları arasındaki ilişkiyi incelerken jeopolitik riski temsil etmesi adına ise jeopolitik risk endeksi kullanılmıştır. Söz konusu endeks Caldara ve Lacoviello (2018) tarafından jeopolitik olaylara ait riskleri içeren makalelerin sıklıkla yayınlandığı ingilizce yayın yapan gazetelerde meydana gelen olay sayılarına göre oluşturulmaktadır. Çalışmada politik risk endeksi ve jeopolitik risk endeksinin yanı sıra Kişi Başına Reel Gayri Safi Yurtiçi Hasıla (GDP), enflasyon oranı (inf), doğrudan yabancı yatırımlar/GDP (\%) (fdi), ve M2/GDP (\%) (M2) değişkenleri kullanılmıştır (Tablo 2). 
Tablo 2: Değiş̧kenler ve Açıklamaları

\begin{tabular}{cccc}
\hline \hline Değişkenler & Değişkenlerin Tanımlanması & Kaynak & $\begin{array}{c}\text { Beklenen } \\
\text { İşaret }\end{array}$ \\
\hline \hline STOCK & $\begin{array}{c}\text { Hisse senedi piyasası kapitalizasyon } \\
\text { değeri/GSYH (\%) }\end{array}$ & Dünya Bankası & + \\
\hline GDP & $\begin{array}{c}\text { Kişi Başına Reel Gayri Safi Yurtiçi Hasıla } \\
\text { (2010 sabit fiyatlarla milyon ABD doları cinsinden) }\end{array}$ & Dünya Bankası- WDI & - \\
\hline PR & Politik Risk Endeksi & $\begin{array}{c}\text { Yazarlar tarafından } \\
\text { hesaplanmışır }\end{array}$ & - \\
\hline GPR & Jeopolitik Risk Indeksi & $\begin{array}{c}\text { Caldara ve } \\
\text { Lacoviello, 2018 }\end{array}$ & $-/+$ \\
\hline INF & Enflasyon Oranı (\%) & Dünya Bankası- WDI & $-/+$ \\
\hline FDI & Doğrudan Yabancı Yatırımlar (Dış Ticaretin \\
GSYH içindeki \% payı) & Dünya Bankası- WDI & + \\
\hline M2 & M2 Para Arzının GSYH içindeki \% payı & Dünya Bankası- WDI & + \\
\hline \hline
\end{tabular}

\subsection{Yöntem}

Yükselen piyasalar ekonomilerinde politik risk ve jeopolitik risk ile hisse senedi piyasaları arasındaki ilişki Parks-Kmenta Tahmincisi yardımıyla analiz edilmiştir. Parks-Kmenta Tahmincisi değişen varyans, otokorelasyon ve birimler arası korelasyondan en az bir tanesinin olması halinde etkin tahminler yapılmasına imkan tanımaktadır. Parks (1967)'nin ele alınan modele ait hata terimlerinde değişen varyansın varlı̆̆ının yanı sıra korelasyon olması durumunda doğrusal bir regresyon modeli tahmin edebilmek amacıyla bir algoritma geliştirmiştir. Kmenta (1986) ise bu modelin mevcut bazı eksikliklerine katkılar sağlayarak söz konusu bu modelin yaygın bir şekilde kullanılmasına öncülük etmiştir. Parks- Kmenta'nın geliştirmiş olduğu model parametre tahminlerine dokunulmadan dirençli standart hatalar elde edilmesini sağlamaktadır. Bu sayede tahmin edilecek modelde değişen varyans, otokorelasyon ve birimler arası korelasyonun en az bir tanesinin olması durumunda bile etkin ve tutarlı tahminler yapılabilir. Ancak böyle bir durumda tahmin edilecek model uygun bir regresyon yapısına kavuşabilmektedir. Buna göre Parks- Kmenta'nın oluşturduğu model yapısı şu şekilde gösterilebilir,

$$
\mathrm{y}_{\mathrm{i}, \mathrm{t}}=\alpha_{\mathrm{i}}+\sum_{\mathrm{k}=2}^{\mathrm{k}} \alpha \mathrm{kx} \mathrm{x}_{\mathrm{kit}}+\mathrm{u}_{\mathrm{it}}
$$

1 nolu eşitlikte verilen sabit terim ve eğim parametrisinin tüm birimler için sabit olduğu ve en küçük karelerle (EKK) kıyaslandığından daha az kısıtlamaya gerek duyan, genelleştirilmiş en küçük kareler (GEKK) yöntemi yardımıyla oluşturulmaktadır. GEKK yöntemi, hata terimlerine ilişkin varyans kovaryans matrisinin $(\Omega)$ bilindiği varsayımı ile tahmin elde etmektedir. Ancak yapılan tahminlerde bu matris bilinmediğinden Esnek Genelleştirilmiş En Küçük Kareler yöntemi tercih edilmektedir. Bu bağlamda değerlendirildiğinde 1 nolu eşitlikteki $\alpha$ katsayılarının tahmin edilmesi için varyans kovaryans matrisinin $(\Omega)$ tutarlı tahmin değerlerinin elde edilmesi yani $\bar{\Omega}$ 'nin bulunması gereklidir (Kmenta,1986: 615).

Öte yandan Parks Kmenta tahmincisinde modelin uygun bir regresyon yapısına sahip olması için ele alınan panel veride yatay kesit boyutu olarak ifade edilen $\mathrm{N}^{\prime}$ in; zaman boyutu T'den küçük olması halinde modelin uygun bir regresyon yapısına kavuşması mümkün olmaktadır. Çünkü Parks Kmenta tahmincisi N>T olması halinde esnek değildir. Diğer bir ifade ile $\mathrm{T}>\mathrm{N}$ olması durumunda tahmincisi daha etkin ve tutarlı sonuçlar vermektedir (Tatoğlu, 2013:277). Bu çalışmada $\mathrm{T}>\mathrm{N}$ durumu geçerli olduğundan daha doğru sonuçlara ulaşabilmek için Parks-Kmenta tahmincisi tercih edilmiştir. 


\section{Ampirik Bulgular}

\subsection{Temel Bileşenler Analizi Sonuçları}

Çalışmada politik risk ve jeopolitik risklerin hisse senedi piyasaları üzerindeki etkilerine iliş̧kin ampirik bulgular sunulmadan önce, Tablo 1'de yer verilen politik risk bileşenlerini dikkate alarak politik risk endeksi (PR) oluşturulacaktır. Söz konusu politik risk endeksini Temel Bileşen Analizi yardımıyla oluşturmak mümkündür. Ancak Temel Bileşenler Analizi yöntemi kullanılmadan önce, seçilen politik risk bileşenlerinin Temel Bileşenler Analizi için uygun olup olmadığına karar verilmesi gerekmektedir. Bunun için ise, Kaiser-Meyer-Olkin (KMO) ve Barlett testleri kullanılmaktadır. Field (2000), Kaiser-Meyer-Olkin testi değeri için alt sınır değerinin 0.50 olması gerektiğini belirtmiştir. Dolasıyla söz konusu test değerinin KMO $\leq 0.50$ olması durumunda seçilen göstergelerin temel bileşenler analizi için faktörlenemeyeceği söylenebilir. Bu doğrultuda KMO değerinin 0,50 değerinden büyük olması ve yapılan Barlett testinin anlamlı olması halinde temel bileşenler analizi yöntemi uygun olacaktır. Buna göre elde edilen Barlett Testi ve Kaiser-Meyer-Olkin testi sonuçlarına Tablo 3'de yer verilmiştir.

Tablo 3: Kaiser-Meyer-Olkin ve Bartlett Testi Sonuçları

\begin{tabular}{ccc}
\hline \hline Kaiser-Mayer-Olkin (KMO) & \multicolumn{2}{c}{0,515} \\
Örneklem Ölçüm Değer Yeterliliği Testi & Ki-Kare & 210,80 \\
\hline \multirow{2}{*}{ Barlett Testi } & Prob. & 0,00 \\
\cline { 2 - 3 }
\end{tabular}

Tablo 3'de yer verilen test sonuçlarına göre KMO test değeri 0,515 olarak elde edilmiştir. Bu sonuç bu çalışmadaki örneklemin faktör analizi için uygun olduğunu göstermektedir. Ayrıca Barlett testi sonucu da istatistiki olarak anlamlıdır. Elde edilen bu sonuçlar politik risk bileşenlerinin birbiriyle ilişkili olduğunu ifade etmektedir. Bu nedenle, Temel Bileşenler Analizi ile politik risk endeksinin oluşturulması için uygun bir yöntemdir. Buna göre elde edilen Temel Bileşen Analizi sonucu elde edilen analiz sonuçları Tablo 4'de verilmiştir.

Tablo 4: Döndürülmemiş Varyans Değerleri

\begin{tabular}{cccc}
\hline \hline Faktör & Özdeğer & Varyans Yüzdesi & Toplam Varyans Yüzdesi \\
\hline \hline Faktör 1 & 1,8582 & 0,3097 & 0,3097 \\
Faktör 2 & 1,1885 & 0,1981 & 0,5078 \\
Faktör 3 & 1,0411 & 0,1735 & 0,6813 \\
\hline \hline
\end{tabular}

Tablo 4'te yer verilen Temel Bileşenler Analizi sonuçlarında özdeğer 1'in üzerinde olan 3 bileşen olduğu için bu değerler dikkate alınarak analiz yapılmıştır. Buna göre söz konusu üç bileşenden birinci bileşenin toplam varyansın \%30,9'ini açıkladı̆̆ı, ikinci bileşenin \%19,8'ini ve üçüncü bileşenin ise \%17,3'ünü açıkladığı görülmektedir. Ayrıca bu üç bileşen politik risk endeksinin oluşturulmasında toplam varyansın \%68'sini oluşturmaktadır. Tablo 5 'te ise seçilen politik risk bileşenlerine karşılık gelen döndürülmüş faktör yükleri verilmiştir. Çalışmada ele alınan faktör analizinde, faktör dağılımlarını daha uygun şekilde görebilmek amacıyla faktör yük değeri 0,20 olarak ele alınmıştır.

Tablo 5: Bileşenler Matrisi Tablosu

\begin{tabular}{cccc}
\hline \hline Göstergeler & Faktör 1 & Faktör 2 & Faktör 3 \\
\hline \hline Demokratik Hesap Verebilirlik ve Ifade Özgürlüğü & 0,634722 & 0,131061 & 0,021154 \\
Politik istikrar ve şiddetin olmaması & 0,208493 & $-0,570454$ & $-0,172840$ \\
Hükümet Etkinliği & 0,583032 & $-0,213125$ & 0,216767 \\
Düzenleyici Kalite & 0,460527 & 0,291532 & $-0,267222$ \\
Kanun ve Düzen & 0,021397 & 0,034909 & 0,922558 \\
Yolsuzluğun Kontrolü & 0,034480 & 0,725103 & $-0,013064$ \\
\hline \hline
\end{tabular}


Tablo 5'te verilen sonuçlara göre 1. bileşende en yüksek faktör yüküne sahip göstergeler; Demokratik Hesap Verebilirlik ve İfade Özgürlüğü, Hükümet Etkinliği, Düzenleyici Kalite ve Politik istikrar ve şiddetin olmaması şeklindedir. Bu göstergeler, politik risk endeksindeki toplam varyansın en yüksek yüzdesini açıklamaktadır. Dolayısıyla bu göstergeler 11 yükselen piyasa ekonomisinde politik riskin en önemli bileşenleridir. Diğer yandan 2. bileşende en yüksek faktör yüküne sahip risk bileşenleri; Yolsuzluğun Kontrolü ve Düzenleyici Kalite şeklindedir. Dolayısıyla bu göstergeler 11 yükselen piyasa ekonomisinde politik riskin ikincil politik risk bileşenleridir. Son olarak 3. bileşende en yüksek faktör yüküne sahip göstergeler; Kanun ve Düzen ve Hükümet Etkinliğidir. Söz konusu bu değerler kullanarak çalışmada politik risk endeksi oluşturulmuş ve çalışmanın bundan sonraki kısmında Temel Bileşenler Analizi yardımıyla elde edilen politik risk endeksi ile hisse senedi piyasaları arasındaki ilişki analiz edilmiştir.

\subsection{Model Tahmin Sonuçları}

Çalışmanın bu kısmında 1 nolu eşitlikte yer verilen Parks- Kmenta Modeli yardımıyla tahmin edilecek model kalıpları oluşturulmuştur. Çalışmada tahmin edilen söz konusu model kalıpları 2 nolu eşitlik ve 3 nolu eşitlikte ifade edilmiştir. 2 nolu eşitlik çalışmada sınanan 1 nolu hipotez ilişkin kurulan Model 1'i ve 2 nolu eşitlik ise 2 nolu hipotezi sınamak üzere kurulan model 2'yi temsil etmektedir. Söz konusu modeller tahmin edilerek tahmin edilerek politik risk ve jeopolitik riskin hisse senedi piyasaları üzerindeki etkisine ilişkin bulgulara yer verilecektir.

Model 1: STOCKit $=\alpha i+b 1$ LOGGDPit +82 INFit+ 63 FDlit + 64 PRit $+65 \mathrm{M} 2 i t+\varepsilon i t$

Model 2: STOCKit $=\alpha i+61$ LOGGDPit + 62 INFit+ 63 FDlit + 64 LOGGPR it + 65M2it+ $i t$ (3)

2 ve 3 nolu eşitlik yardımıyla tahmin edilecek modele ilişkin temel hipotez ise şu şekilde ifade edilebilir:

H1: Politik risk seviyesinin hisse senedi piyasaları üzerinde doğrudan bir etkisi vardır.

H2: Jeopolitik risk seviyesinin hisse senedi piyasaları üzerinde doğrudan bir etkisi vardır.

Söz konusu bu hipotezlere göre ülkelerin sahip olduğu risk düzeyinin yarattığı belirsizlik yatırımcı tarafından yatırım yapmama ya da yatırımı erteleme kararıyla sonuçlanmaktadır. Bu ise hisse senedi piyasalarına doğrudan bir etkiyle sonuçlanacaktır. Ayrıca bu hipotezlerin sınanması için kullanılan değişkenlere ilişkin tanımlayıcı test istatistikleri Tablo 6'da verilmektedir.

Tablo 6: Değişkenlere iliş̧kin Tanımlayıcı Test İstatistikleri

\begin{tabular}{ccccc}
\hline \hline Değişkenler & Ortalama & Standart Sapma & Minimum & Maksimum \\
\hline \hline STOCK & 0,7173367 & 0,6548566 & 0,0627397 & 3,521564 \\
GDP & 6389,219 & 3405,626 & 869,201 & 15068,98 \\
PR & $2,14 \mathrm{e}-09$ & 1,214385 & $-3,064399$ & 2,508 \\
GPR & 97,43278 & 23,4371 & 44,68 & 176,11 \\
INF & 0,0671141 & 0,0743366 & $-0,0090042$ & 0,4496412 \\
FDI & 0,0234891 & 0,0122656 & $-0,0025426$ & 0,0702889 \\
M2 & 0,7365251 & 0,4571511 & 0,2349367 & 2,076737 \\
\hline \hline
\end{tabular}


Yükselen piyasa ekonomilerinde politik risk ve jeopolitik risk ile hisse senedi piyasası arasındaki ilişkinin tespiti için öncelikle, panel veriyi oluşturan ülkeler için birimler arası korelasyonun varlığının tespiti yani yatay kesit bağımlılığının incelenmesi gerekmektedir. Bu bağlamda çalışmada analize geçilmeden önce ilk olarak yatay kesit bağımlılık testleri yapılmıştır. Diğer bir ifade ile seride yaşanan bir şokun yatay kesitlerin tümü için aynı dereceden etkisinin olup olmadığı test edilmiştir (Akçay ve Erataş, 2012:12). Breusch ve Pagan(1980) ile Pesaran (2004)'ün de ifade ettiği üzere yapılacak panel veri analizinde değişkenler arasında yatay kesit bağımlılığının bulunması analiz sonuçlarını önemli ölçüde etkilediği için, ulaşılan sonuçların tutarsız ve dengeden sapmalı olmasını önlemek adına, serilerde yatay kesit bağımlılı̆ının varlığı test edilmelidir. Bu çerçevede çalışma da ele alınan panel veri setine ilişkin örneklemde zaman sürecindeki gözlem sayısını ifade eden $T$, panel verideki yatay kesitlerin toplamını ifade eden $\mathrm{N}$ sayısından büyük olduğundan Breusch ve Pagan(1980) tarafından geliştirilmiş olan ve eşitlik 4'te yer verilen LM yatay kesit bağımlılığı testi yapılmıştır.

$$
L M=T\left(\sum_{i=1}^{N-1} \sum_{j=i+1}^{N} \rho \mathrm{ij} 2 \sim \chi^{2} \frac{\mathrm{N}(\mathrm{N}(-1)}{2} \sum_{j=i+1}^{N} \rho \mathrm{ij} 2 \sim \chi^{2} \frac{\mathrm{N}(\mathrm{N}(-1)}{2}\right)
$$

Eşitlik 4 yardımıyla elde edilen yatay kesit bağımlılığı testi sonuçlarına ise Tablo 7'de yer verilmiştir.

Tablo 7: Yatay Kesit Bağımlılığına Ait Test Sonuçları

\begin{tabular}{ccc}
\hline \hline & Model 1 & Model 2 \\
\hline \hline Test & ístatistik Değeri & istatistik Değeri \\
\hline LM testi & 319,42 & 302,85 \\
\hline LM Testi P değeri & 0,00 & 0,00 \\
\hline \hline
\end{tabular}

Tablo 4'deki LM testi sonuçlarına göre, yükselen piyasa ekonomilerinde yatay kesit bağımlıığının olmadığını ifade eden boş hipotez her iki modelde de reddedilmektedir. Elde edilen bu sonuç, paneli oluşturan birimler arasında yatay kesit bağımlılığın olduğu şeklinde değerlendirilebilir. Çalışmada yatay kesit bağımlıı̆ı̆ından sonra ise değişkenlerin durağanlık özellikleri incelenmiştir. Çalışmada kullanılan panel veride yatay kesit bağımlılığı tespit edildiği için, değişkenlerin durağanlıkları 2. Nesil birim kök testlerinden, Eşitlik 4'de ifade edilen Pesaran (2007) CIPS birim kök testi kullanılmıştır. Eşitlik 5 yardımıyla CIPS tahmincisinin uygulanması ile ulaşılan test sonuçlarına ise Tablo 8'de yer verilmiştir.

$\mathrm{CIPS}=\mathrm{N}^{-1} \sum_{j=1}^{n} \mathrm{CADF}$

Tablo 8: Değişkenleri Ait Birim Kök Testi Sonuçları

\begin{tabular}{cc}
\hline \hline Değişken Adı & CIPS Test İstatistiği \\
\hline \hline STOCK & 0,675 \\
STOCK & $-4,825^{* * *}$ \\
LOGGDP & 2,184 \\
$\Delta$ LOGGDP & $-4,539^{* * *}$ \\
PR & 0,593 \\
$\Delta$ PR & $-7,044^{* * *}$ \\
LOGGPR & 0,354 \\
$\Delta$ LOGGPR & $-4,307^{* * *}$ \\
INF & $-3,25^{* * *}$ \\
FDI & $-3,68^{* * *}$ \\
\hline \hline
\end{tabular}

$\overline{\text { Not: Testlerin deterministik spesifikasyonu sabit ve trendi içermektedir. Ayrıca } * 0,10,{ }^{* *} 0,05 \text { ve } * * * 0,01 \text { anlamlılık }}$ düzeylerini göstermektedir. 
Tablo 8'de verilen birim kök testleri sonucuna göre çalışmada kullanılan değişkenlerden INF ve FDI değişenlerinin orijinal hallerinde birim kök içermediği, yani I(0) düzeyinde durağan oldukları görülmektedir. Öte yandan, STOCK, GDP, PR ve GPR değişkeni için ise I(0) yani düzeyde durağan olmadığı, ancak I(1) düzeyinde yani birinci farkı alındığında durağanlaştığı görülmektedir.

Çalışmada bir sonraki aşamada ise, model tahmin sonuçlarında hatalara ve sapmalara yol açabilen değişen varyans probleminin gözlenip gözlenmediğinin tespiti için değiştirilmiş Wald Testi yapılmıştır. Modelde otokorelasyon probleminin tespiti için ise Wooldridge otokorelasyon testi yapılmış ve söz konusu test sonuçları Tablo 9'da ifade edilmiştir.

Tablo 9: Değişen Varyans ve Otokorelasyon Test Sonuçları

\begin{tabular}{ccc}
\hline \hline & Model 1 & Model 2 \\
\hline \hline Test Adı & Test İstatistiği & Test İstatistiği \\
\hline Değiştirilmiş Wald Testi & $5712(0.00)^{* * *}$ & $5169(0,00)^{* * *}$ \\
Wooldridge otokorelasyon testi & $2,349(0.15)$ & $1.31(0,27)$ \\
\hline \hline
\end{tabular}

Not: () değişkenlerin olasılık değerlerini ifade etmektedir. Ayrıca * 0,10, **0,05 ve *** 0,01 anlamlılık düzeylerini göstermektedir.

Tablo 9'da yer verilen test sonuçlarından da görüldüğü üzere çalışmada ele alınan her iki modelde de elde edilen değişen varyans testine ait olasılık değeri \%5 anlamlılık düzeyinden küçük olması nedeniyle modelde değişen varyans sorunu tespit edilmiştir. Bununla birlikte yapılan Wooldridge otokorelasyon testi sonuçları ise kurulan her iki modelde de otokorelasyon sorunun bulunmadığını göstermektedir. Daha öncede vurgulandığı üzere ele alınan modellerde değişen varyans sorunu, otokorelasyon sorunu ve birimler arası korelasyon varlığından en az bir tanesinin olması ve aynı zamanda $\mathrm{T}>\mathrm{N}$ olması durumunda Parks-Kmenta Tahmincisi yardımıyla daha etkin tahmin sonuçları elde edilmektedir. Bu nedenle çalışmada değişen varyans ve birimler arası korelasyonun varlı̆̆ı ve $T>N$ durumunun geçerli olması nedeniyle model Parks-Kmenta tahmincisi yardımıyla tahmin edilmiş ve Tablo 10 'da bu sonuçlar verilmiştir.

Tablo 10: Parks-Kmenta Tahmin Sonuçları

\begin{tabular}{cccc}
\hline \hline & Model 1 & \multicolumn{2}{c}{ Model 2 } \\
\hline \hline Değişkenler & Katsayılar & Değişkenler & Katsayılar \\
\hline$\Delta$ LOGGDP & $0,29(5,04)^{* * *}$ & $\Delta$ LOGGDP & $0,02(0,19)$ \\
INF & $-0,32(8,89)^{* * *}$ & INF & $-0,24(-4,62)^{* * *}$ \\
FDI & $-3,00(-11,43)^{* * *}$ & FDI & $-2,36(-6,23)^{* * *}$ \\
$\Delta$ PR & $-0,01(-4,40)^{* * *}$ & $\Delta$ LOGGPR & $-0,09(-4,04)^{* * *}$ \\
$\Delta$ M2 & $0,42(5,80)^{* * *}$ & $\Delta$ M2 & $0,24(1,77)^{*}$ \\
C & $0,09(10,91)$ & $C$ & $0,08(6,18)^{* * *}$ \\
\hline & Wald & & Wald \\
Gözlem Sayısı & İstatistik: & & İstatistik: \\
& 304,06 & 78,03 \\
\hline
\end{tabular}

Not: Parantez içindeki değerler z istatistik değerleridir. Ayrıca ${ }^{*} 0,10,{ }^{*} 0,05$ ve ${ }^{* * *} 0,01$ anlamlılık düzeylerini göstermektedir. 
Tablo 10'da yer verilen Parks-Kmenta tahmin sonuçlarına göre gelir artışının hisse senedi piyasaları üzerindeki etkisi beklendiği gibi pozitif olarak bulunmuştur. Ancak bu etki politik riskin hisse senedi piyasaları üzerine etkilerinin analiz edildiği Model 1'de istatistiki olarak anlamlı olarak bulunurken, jeopolitik riskin hisse senedi piyasaları üzerine etkilerinin analiz edildiği Model 2'de ise istatistiki olarak anlamlı değildir. Elde edilen bu sonuç genel ekonomik faaliyetin bir göstergesi olan GSYH'nin mevcut literatürde de ele alındığı gibi hisse senedi piyasaları üzerindeki etkilerinin belirsizliğinden kaynaklanmaktadır. Örneğin Levchenko ve Mauro (2007), Model 2'de yer verilen sonuçlarla benzer şekilde GSYH'nin hisse senedi piyasaları üzerinde anlamlı bir etkisi ortaya olmadığı sonucuna varırken, Thapa ve Poshakwale (2010) ise GSYH büyümesinin hisse senedi piyasaları üzerinde anlamlı bir etkisi olduğunu, ancak tüm ülkeler için anlamlı olmadığı sonucuna varmıştır. Öte yandan Diebold ve Yılmaz (2008) ise Model 1 ile benzer şekilde hisse senedi ile GSYH arasında pozitif bir ilişki bulmaktadır. Dolayısıyla çalışmada elde edilen bulgularında gösterdiği gibi literatürle paralel şekilde GSYH ile hisse senedi piyasaları arasındaki ilişki farklı bulgular ortaya koyabilmektedir.

Çalışmada ele alınan diğer bir değişken olan enflasyonun hisse senedi piyasaları üzerinde her iki modelde de istatistiki olarak anlamlı ve negatif bir etkisi olduğu sonucuna ulaşılmıştır. Boyd vd (2001)'in ifade ettiği gibi daha yüksek enflasyon oranları, daha az uzun vadeli finansal faaliyet anlamına gelmektedir. Dolayısıyla enflasyon artışı durumunda, aracılar daha az borç verecek ve daha az etkinlikte sermaye tahsisinde bulunulacaktır. Bu ise hisse senedi piyasaları için daha küçük hacimli ve daha az likit bir piyasa anlamına geldiğinden hisse senedi piyasaları enflasyon artışından olumsuz etkilenecektir. Öte yandan, doğrudan yabancı yatırımlarındaki artış ile hisse senedi piyasaları arasında her iki modelde de istatistiki olarak anlamlı ve negatif bir ilişki olduğu bulgusu elde edilmiştir. Yani yükselen piyasalar ekonomilerinde daha yüksek doğrudan yabancı yatırımı artışı hisse senedi piyasasını olumsuz etkilemekte olduğu anlamına gelmektedir. Elde edilen bu bulgu Hausman ve Fernan (2000) ile Malcus ve Persson (2018) ile benzer şekilde, yabancı yatırımcıların yerel borsada yatırım yapmak yerine doğrudan yabancı yatırımcıları seçebileceği şeklinde değerlendirilebilir. Diğer bir anlatımla bu bulgu doğrudan yabancı yatırımların hisse senedi piyasalarının ikamesi olduğunu ima etmektedir.

Çalışmanın temel araştırma konusunu oluşturan politik risk (Model 1) ve jeopolitik riskin Model 2) ise hisse senedi piyasaları üzerinde negatif ve istatistiki olarak anlamlı bir etkisi olduğu görülmektedir. Dolasıyla elde edilen bu bulgu, hisse senedi piyasalarının yükselen piyasa ekonomilerinin politik ve jeopolitik risklere karşı duyarlılığının yüksek olduğunu ifade etmektedir. Yani; yükselen piyasa ekonomilerinde ekonomik göstergelerin durumuna bakılmaksızın politik risk ve jeopolitik risk artışlarının yatırımcılarının yatırım kararı alma sürecini olumsuz etkileyerek hisse senedi piyasalarında bozucu etkiler yaratmaktadır.

Hisse senedi piyasaları üzerindeki etkisinin araştırıldığı diğer değişken ise $M 2$ 'dir. Çalışmada M2'deki artışın her iki modelde de hisse senedi piyasaları üzerinde istatistiki olarak anlamlı ve iyileştirici bir etkisinin olduğu bulunmuştur. Söz konusu değişken literatürde yer alan finansal gelişmeyi temsil eden M2/GSYH (\%) olarak analize dahil edildiği için, yükselen piyasa ekonomilerinde finansal gelişme düzeyinin hisse senedi piyasalarını olumlu şekilde etkilediği yorumu yapılabilir. Diğer bir ifade ile finansal gelişme artışı ile birlikte sermayeye erişim daha kolay olacağından, yatırımcılar için finansal kaynaklar finansal gelişmeyle paralel şekilde artacaktır. Dolasıyla finansal gelişmedeki iyileşmeler yatırım ortamında iyileşmelere neden olacağından hisse senedi piyasasını olumlu olarak etkileyecektir. Bu sonuç Laopodis (2013)'le paraleldir. 


\section{Sonuç}

Hisse senedine yatırım riskli olduğundan, yatırımcıların yatırım kararı alma sürecini etkileyen birçok faktör bulunmaktadır. Bu faktörlerden biri de ülkenin sahip olduğu risk düzeyidir. Risk düzeyinin yüksek olduğu ülkelerde, bu durum bir belirsizlik ortamı yaratmakta ve yatırııımlar açısından yatırım kararlarından vazgeçme ya da erteleme şeklinde sonuçlanabilmektedir. Dahası yatırımcıların yatırım kararı alma sürecinde özellikle yükselen ve sığ piyasalarda şirketlerin varlıklarını kaybetme olasılığı göz önüne alındığında, ülkelerin sahip olduğu risklilik düzeyi daha da önemli bir unsur haline gelmektedir. Bu kapsamda düşünüldüğünde çalışmada risk düzeyinin iki temel bileşeni olan politik risk ve jeopolitik riskin hisse senedi piyasalarını etkileyip etkilemediği analiz edilmiştir. Söz konusu unsurlardan politik risk siyasi ortamda meydana gelen değişikliklerin beraberinde getirdiği politik risklerin hisse senedi piyasalarına etkilerine göstermesi bakımından önemli bir unsur olarak görülmektedir. Benzer şekilde bulunduğu coğrafyada meydana gelen karışılıkların beraberinde getirdiği jeopolitik risklerde hisse senedi piyasaları üzerinde diğer önemli bir unsurdur.

Bu bağlamda çalışmada risklilik düzeyinin hisse senedi piyasaları için öneminden hareketle, 11 yükselen piyasa ekonomisinde politik risk ve jeopolitik riskler ile hisse senedi piyasaları arasındaki ilişkin araştırılması hedeflenmiştir. Bu ise 2005-2018 yılları arasındaki verileri içeren panel veri seti ve Temel Bileşenler Analizi (PCA) yöntemi, Parks-Kmenta Tahmincisi yardımıyla analiz edilmiştir. Çalışmada ilk aşamada Temel Bileşenler Analizi (PCA) yöntemi kullanılarak, politik risk bileşenlerinin göreceli önemi elde edilmiş ve 11 yükselen piyasa ekonomisi için yeni bir politik risk endeksi oluşturulmuştur. Buna göre politik risk bileşenlerinden göreceli olarak en önemli politik risk bileşenleri demokratik hesap verebilirlik ve ifade özgürlüğü, hükümet etkinliği, düzenleyici kalite, politik istikrar ve şiddetin olmaması şeklindedir. Dolasıyla bu politik risk bileşenleri, 11 yükselen piyasa ekonomisinde politik riskin göreceli olarak en önemli politik risk bileşenleri olduğu şeklinde değerlendirilebilir.

Çalışmada Parks-Kmenta Tahmincisi yardımıyla elde edilen ampirik sonuçlara göre ise, politik risk ve jeopolitik risk artışlarının hisse senedi piyasaları üzerindeki etkisi negatif ve istatistiki olarak anlamlı olarak bulunmuştur. Bu sonuç, yükselen piyasa ekonomilerinde siyasi ortamda meydana gelen değişiklikler ve bulundukları coğrafyada meydana gelen karışıklıkların yarattığı belirsizliklerin hisse senedi piyasalarına olumsuz olarak yansıdığı şeklinde değerlendirilebilir. Bilindiği üzere, hisse senedi gibi yüksek riskli yatırım araçlarına yatırım yapan yatırımcılar, belirsizlik durumlarında negatif getiriyle karşı karşıya kaldıklarından, bu piyasalara yatırım yapmaktan vazgeçmektedir. Bu ise, yatırımcıların daha düşük katılımını meydana getirdiğinden hisse senedi piyasalarını olumsuz yönde etkilemektedir. Dolayısıyla politik risk ve jeopolitik risk artışları durumunda yatırımcıların riskten kaçınma davranışı içinde olmaları nedeniyle, hisse senedi piyasaları olumsuz yönde etkilenmektedir. Diğer bir ifade ile siyasi belirsizlikler ve coğrafik karışıklar, yükselen piyasalar ekonomilerine yönelik algıları olumsuz etkileyerek hem yerli hem de yabancı yatırımcıların hisse senedi piyasalarına yapacakları yatırımları sınırlandırmaktadır. Elde edilen bu sonuçlar, Kaya vd. (2014), Lehkonen ve Heimonen (2015), Vargas ve Silva (2019)'in politik riskin hisse senedi piyasaları üzerine etkilerini araştırdığı çalışmasıyla tutarlıdır. Benzer şekilde elde edilen ampirik bulgular, Bezgin (2019) ile Hoque ve Zaidi (2020)'in jeopolitik riskin hisse senedi piyasaları üzerine etkilerini araştırdığı çalışma sonuçlarıyla paraleldir.

Bulgulardan çıkarılan bir diğer sonuç ise, politik risk ve jeopolitik risklerin hisse senedi piyasalarına olan negatif etkilerinin düzeyi üzerinedir. Analiz sonuçlarının da gösterdiği üzere 
jeopolitik riskin hisse senedi piyasaları üzerindeki negatif etkisi politik risklerden daha fazla olduğu bulgusuna ulaşılmıştır. Bu nedenle, jeopolitik risk unsurlarının hisse senedi piyasaları üzerinde daha yüksek düzeyde olumsuz etkileri olduğu şeklinde yorumlanabilir. Dolasıyla Antonakakis vd.'nin (2017) de belirttiği gibi jeopolitik risk belirli olayların piyasa ve yatırımları nasıl etkilediğinin incelenmesinde, daha güvenilir çıkarımlar ortaya koymaktadır.

Sonuç olarak çalışmada elde edilen bulgular çerçevesinde, hisse senedi piyasaları için politik ve jeopolitik risklerin azaltılması ve ekonomik ortamın iyileştirilmesine bağlı olarak yatırımlar için elverişli bir ortam yaratılabilmektedir. Yani siyasi belirsizlikler, coğrafi karışıklıkların hisse senedi piyasalarının performansını kötüleştiren koşulların önlenmesi halinde hisse senedi piyasalarının yatırımcı çekme algısını iyileştirmesi mümkün gözükmektedir. Bu koşulların sağlanması halinde, yatırımcıların belirsizlik ve risklilik düzeyi düşmekte ve yerli ve yabancı yatırımcıları hisse senedi piyasalarına yatırımlarını artırmaktadır. $\mathrm{Bu}$ doğrultuda çalışmada elde edilen bulgular politika karar alıcılarına, hisse senedi piyasalarına daha çok yatırım çekmek için mutlak suretle politik riskleri ve jeopolitik riskleri azaltıcı, ekonomik ortamı iyileştirici ve finansal gelişmeyi teşvik edici politikalar geliştirmeleri gereğini göstermektedir. 


\section{Kaynakça}

Afşar, A. ve Doğan E. (2018). Politik risklerin hisse senedi piyasaları üzerine etkileri: Ampirik bir analiz. 22. Finans Sempozyumu içinde (993-1003), Mersin.

Akçay, A. Ö. ve Erataş, F. (2012). Cari açık ve ekonomik büyüme ilişkisinin panel nedensellik analizi ekseninde değerlendirilmesi. Türkiye Ekonomi Kurumu, UEK-TEK 2012 izmir, 1-24.

Antonakakis, N., Gupta, R., Kollias, C., \& Papadamou, S. (2017). Geopolitical risks and the oil-stock nexus over 1899-2016. Finance Research Letters, 23, 165-173.

Bekaert, G., Harvey, C. R., Lundblad, C. T., \& Siegel, S. (2014). Political Risk Spreads. Journal of International Business Studies, 45(4), 471-493.

Bezgin, M. S. (2010). Türkiye'nin Jeopolitik Riski'nin Borsa İstanbul Endeks Getirileri Üzerine Etkisinin Incelenmesi.

Bilson, C. M., Brailsford, T. J., \& Hooper, V. C. (2002). The Explanatory Power of Political Risk in Emerging Markets. International Review of Financial Analysis, 11(1), 1-27.

Boyd, J. H., Levine, R., \& Smith, B. D. (2001). The impact of inflation on financial sector performance. Journal of monetary Economics, 47(2), 221-248.

Breusch, T. S ve Pagan, A. R. (1980), The Lagrange Multiplier Test and its applications to model specification tests in econometrics", Review of Economic Studies, 47, 239-53.

Butler, K. C., \& Joaquin, D. C. (1998). A note on political risk and the required return on foreign direct investment. Journal of International Business Studies, 29(3), 599-607.

Caldara, D., \& lacoviello, M. (2018). Measuring geopolitical risk. FRB International Finance Discussion Paper, (1222).

Çam, A.V. (2014). Politik Riskin Firma Değeri ile Illişkisi: IMKB'ye Kayıtlı Firmalar Üzerinde Bir Uygulama. Doğuş Üniversitesi Dergisi, 15(1), 109-122.

Çetin, Ö. G. D. T. Türkiye'de Jeopolitik Risk ve İslami Hisse Senedi Endeksi Arasındaki Nedensellik iliş̧isi: Ampirik Bir Analiz. In International Congress of Islamic Economy, Finance and Ethics (p. 108).

Das, D., Kannadhasan, M., \& Bhattacharyya, M. (2019). Do the emerging stock markets react to international economic policy uncertainty, geopolitical risk and financial stress alike?. The North American Journal of Economics and Finance, 48, 1-19.

De Santis, G. (1997). Stock returns and volatility in emerging financial markets. Journal of International Money and finance, 16(4), 561-579.

Diamonte, R. L., Liew, J. M., \& Stevens, R. L. (1996). Political Risk in Emerging and Developed Markets. Financial Analysts Journal, 52(3), 71-76.

Diebold, F. X., \& Yilmaz, K. (2008). Macroeconomic volatility and stock market volatility, worldwide: National Bureau of Economic Research.

Dimic, N., Orlov, V., \& Piljak, V. (2015). The Political Risk Factor in Emerging, Frontier and Developed Stock Markets. Finance Research Letters, 15, 239-245.

Estrin, S., \& Uvalic, M. (2013). Foreign Direct Investment into Transition Economies: Are the Balkans Different?. LSE ‘Europe in Question' Discussion Paper Series, No. 64/2013, 5-42.

Field, A. (2000). Discovering Statistics using SPSS for Windows. London, Thousand Oaks, Sage Publications, New Delhi.

Gärtner, M., \& Wellershoff, K. W. (1999). Theories of Political Cycles: Lessons from the American Stock Market. International Review of Economics, 46(4), 22-39.

Hausmann, R. and Fernández-Arias, E. (2000). “Foreign direct investment: goodcholesterol?". Inter American Development Bank Working Paper 417, New Orleans, April.

Hoque, M. E., \& Zaidi, M. A. S. (2020). Global and country-specific geopolitical risk uncertainty and stock return of fragile emerging economies. Borsa Istanbul Review, 20(3), 197-213.

Johnson, R. A. and Wichern, D. W. 2002. Applied multivariate statistical analysis (Vol. 5, No. 8). Upper Saddle River, NJ: Prentice hall. 
Kaya, A., Güngör, B., \& Özçomak, M.S. (2014). Politik Risk Yatırımcının Dikkate Alması Gereken Bir Risk Midir? Borsa İstanbul Örneği. İktisadi ve İdari Bilimler Fakültesi Dergisi, 16(1), 74-87.

Kmenta, Jan (1986), Elements of Econometrics (Second ed.), New York: Macmillan, pp. 302-320.

Kobbi, H., \& Abdelhedi, M. (2018). The Effect of Political Instability and Terrorism on Tunisian Financial Market. IUP Journal of Applied Economics, 17(1), 7-16.

Laopodis, N.T, (2013). Monetary policy and stock market dynamics across monetary regimes, Journal of International Money and Finance, www.elsevier.com/locate/jimf

Lehkonen, H., \& Heimonen, K. (2015). Democracy, Political Risks and Stock Market Performance. Journal of International Money and Finance, 59, 77-99.

Levchenko, A. A., \& Mauro, P. (2007). Do some forms of financial flows help protect against "sudden stops"? The World Bank Economic Review, 21(3), 389-411.

Malcus, R., \& Persson, M. (2018). The Impact of Foreign Direct Investment on the Stock Market Development in Sweden.

Mei, J., \& Guo, L. (2004). Political Uncertainty, Financial Crisis and Market Volatility. European Financial Management, 10(4), 639-657.

Minovic, J., \& Eric, D. (2016). Impact of Political Risk on Frontier Capital Market. Engineering Economics, 27(2), 151-162.

Özdamar, K. 2010. Paket programlar ile istatistiksel veri analizi-2 (Çok değişkenli analizler). Kaan Kitabevi, Eskişehir.

Parks, R. (1967), Efficient Estimation of a System of Regression Equations When Disturbances Are Both Serially and Contemporaneously Correlated, Journal of the American Statistical Association, 62: 500-509.

Perotti, E. C., \& Van Oijen, P. (2001). Privatization, Political Risk and Stock Market Development in Emerging Economies. Journal of International Money and Finance, 20(1), 43-69.

Pesaran, Hashem M. (2007). A simple panel unit root test in the presence of Cross-Section Dependence. Journal of Applied Econometrics, 22 (2), 265-312.

Pesaran, Hashem M. (2004).General Diagnostic Tests for Cross Section Dependence in Panels. IZA Discussion Papers, 1240, 1-39.

Tatıdil, H. 2002. Uygulamalı çok değişkenli istatistiksel analiz. Cem Web Ofset Ltd, 424, Ankara.

Tatoğlu, F. Yerdelen (2013). Panel Veri Ekonometrisi (2. Baskı). İstanbul: Beta Yayınevi.

Thapa, C., \& Poshakwale, S. S. (2010). International equity portfolio allocations and transaction costs. Journal of Banking \& Finance, 34(11), 2627-2638

Tolstova, E., \& Kapolková, J. (2015). The Impact of Political Risk on Equity Market Performance.

Tuncay, M. (2018). Do Political Risks Matter in the Financial Markets?: Evidence From Turkey. Eurasian Business Review, 8(2), 209-227.

Tükenmez, N. M., \& Kutay, N. (2016). Ülke Riskinin Hisse Senetleri Getirileri Üzerine Etkisi: Türkiye ve Arjantin Piyasaları İ̧̧in Bir Karşılaştırma. Atatürk Üniversitesi Sosyal Bilimler Enstitüsü Dergisi, 20(2), 631645.

Vargas, K., Gonzalez, A., \& Silva, J. (2019, June). The effect of global political risk on stock returns: a cross-sectional and a time-series analysis. In International Conference on Intelligent Computing, Information and Control Systems (pp. 540-548). Springer, Cham.

Vortelinos, D. I., \& Saha, S. (2016). The Impact of Political Risk on Return, Volatility and Discontinuity: Evidence From The International Stock and Foreign Exchange Markets. Finance Research Letters, 17, 222-226.

Waszkiewicz, G. (2017). Political Risk on Financial Markets in Developed and Developing Economies. Journal of Economics \& Management, 28, 112-132. 


\section{How Political and Geopolitical Risks Affect Stock Markets: Empirical Evidence from Emerging Market Economies}

The liberalization of financial markets and the globalization of capital markets have improved financial services and investment. At the same time, this has been an important factor in bringing accessible and profitable investment to countries. There are many factors for the arrival of accessible and profitable investments in the country. These factors include macroeconomic indicators such as the market structure of the country, economic and financial stability, and exchange rate risks. In addition, the increase in the element of uncertainty for investors has important implications for the financial markets as it occupies an important place in determining accessible and profitable investments. One of the main determinants in determining these uncertainties is the level of risk of countries. It is well known that the high-risk level of countries creates an element of uncertainty for foreign investment. This can lead to investors either abandoning their current investments or postponing their investment plans. In view of this, it is important to develop an understanding of the impact of political and geopolitical risks on equities and therefore on financial markets, which are among the factors that make up a country's risk level.

As stated earlier in countries where the level of risk is high, this creates an atmosphere of uncertainty and may cause investors to abandon or postpone their investment decisions. Furthermore, when considering the possibility that companies may lose their assets, especially in emerging and flat markets, the risk level of countries becomes an even more important factor in the investment decision process of investors. In this context, this study analyzed whether political risk and geopolitical risk, which are the two main components of risk level, affect stock markets. Among these factors, political risk is considered as an important factor to show the impact of political risk caused by the changes in the political environment on stock markets. Similarly, the geopolitical risks caused by the unrest in the geography is another important factor for the stock markets.

In this context, based on the importance of risk level for stock markets, an attempt is made to examine the relationship between political risk and geopolitical risk and stock markets in 11 emerging markets. This panel data set, which contains the data between 2005-2018, was analyzed using the Principal Components Analysis (PCA) and Parks-Kmenta Estimator method. In the first phase of the study, the relative importance of political risk components was determined using Principal Components Analysis (PCA) method and a new political risk index was constructed for 11 emerging markets. According to this, the most important political risk components are democratic accountability and freedom of expression, government effectiveness, regulatory quality, political stability, and absence of violence. Therefore, these political risk components can be evaluated as the most important political risk components in 11 emerging countries.

According to the empirical results obtained using Parks-Kmenta Estimator, it was found that the effect of political risk and increase in geopolitical risk on stock markets is negative and statistically significant. This result can be interpreted to mean that the changes in the political environment in emerging markets and the uncertainties created by the unrest in their geography have a negative impact on the stock markets. It is a known fact that investors who invest in risky investment instruments such as equities abandon their investments in these markets as they face negative returns in uncertain situations. This in turn has a negative impact on the equity markets as it leads to lower investor participation. Thus, when political and geopolitical risk increases, equity markets are negatively affected due to investors' risk-averse behavior. In other words, political uncertainty and geographic unrest negatively affect the perception of emerging markets and limit the investment of domestic and foreign investors in the stock markets. These findings by Kaya et al. (2014), Lehkonen and Heimonen (2015) are consistent with the study by Vargas and Silva (2019), which examines the impact of political risk on equity markets. Similarly, the empirical results are consistent with the findings of Bezgin (2019) and Hoque and Zaidi (2020) study which examine the impact of geopolitical risk on stock markets. Another conclusion drawn from the results relates to the level of the negative impact of political risk and geopolitical risk on equity markets. As the results of the analysis show, it was found that the negative effect of geopolitical risk on stock markets is greater than political risk. For this reason, it can be interpreted that the political turmoil, institutional struggles and behaviors, undemocratic processes, and geopolitical risk factors such as terrorist attacks that have emerged as a result of political activities in the country have a higher degree of negative impact on stock markets. Therefore, as noted by Antonakakis et al. (2017), geopolitical risk allows for more reliable inferences when examining how certain events affect the market and investments.

Consequently, in the context of the findings in the study, it is possible to create a favorable environment for investment depending on the reduction of political and geopolitical risks to the stock markets and the improvement of the economic environment. In other words, it seems possible that stock markets improve the perception of attraction for investors if political uncertainties, geographical unrest, and conditions that worsen the performance of stock markets are prevented. When these conditions are met, the level of investor uncertainty and risk decreases, and domestic and foreign investors increase their investment in equity markets. In this direction, the evidence obtained in the study shows that policymakers should develop policies that reduce political and geopolitical risks, improve the economic environment and promote financial development to attract more investment in stock markets. 